oPEN A Series RCL Circuit Theory for Analyzing Non-Steady-State Water Uptake of

SUBJECT AREAS:

ECOLOGICAL

MODELLING

ECOPHYSIOLOGY

Received

8 May 2014

Accepted

3 October 2014

Published

22 October 2014

Correspondence and requests for materials should be addressed to J.Z. (jzhuang@utk.edu) \title{
Maize Plants
}

\author{
Jie Zhuang ${ }^{1,2}$, Gui-Rui Yu³ \& Keiichi Nakayama ${ }^{4}$
}

\begin{abstract}
${ }^{1}$ Key Laboratory of Pollution Ecology and Environmental Engineering, Institute of Applied Ecology, Chinese Academy of Sciences, Shenyang, China, ${ }^{2}$ Department of Biosystems Engineering and Soil Science, Institute for a Secure and Sustainable Environment, The University of Tennessee, Knoxville, TN 37996, USA, ${ }^{3}$ Institute of Geographic Science and Natural Resources Research, Chinese Academy of Sciences, Beijing, China, ${ }^{4}$ Faculty of Horticulture, Chiba University, Matsudo, Japan.
\end{abstract}

Understanding water uptake and transport through the soil-plant continuum is vital for ecosystem management and agricultural water use. Plant water uptake under natural conditions is a non-steady transient flow controlled by root distribution, plant configuration, soil hydraulics, and climatic conditions. Despite significant progress in model development, a mechanistic description of transient water uptake has not been developed or remains incomplete. Here, based on advanced electrical network theory (RLC circuit theory), we developed a non-steady state biophysical model to mechanistically analyze the fluctuations of uptake rates in response to water stress. We found that the non-steady-state model captures the nature of instantaneity and hysteresis of plant water uptake due to the considerations of water storage in plant xylem and coarse roots (capacitance effect), hydraulic architecture of leaf system (inductance effect), and soil-root contact (fuse effect). The model provides insights into the important role of plant configuration and hydraulic heterogeneity in helping plants survive an adverse environment. Our tests against field data suggest that the non-steady-state model has great potential for being used to interpret the smart water strategy of plants, which is intrinsically determined by stem size, leaf size/thickness and distribution, root system architecture, and the ratio of fine-to-coarse root lengths.

he modeling of hydrologic cycles in terrestrial and agricultural ecosystems and the evaluation of the tolerance of plants to water stress requires a mechanistic description of the uptake and transport of soil water through the soil-plant continuum ${ }^{1-4}$. Thus, many models have been developed ${ }^{5-20}$. The cohesiontension theory ${ }^{21}$ and the classical catenary hypothesis (or Ohm's Law analogue) $)^{22,23}$ provide important conceptual frameworks for a mechanistic understanding of plant-water relationships $s^{24,25}$. The model based on Ohm's Law (i.e., van den Honert's model) views water flow through plants as analogous to electric current through a resistance network. In the past decade, this model was adjusted to account for the storage of water in the stem, branches, and leaves by inclusion of one or more hydraulic plant capacitances (see reviews ${ }^{26,27}$ ). This adjustment led to the development of dynamic flow and storage models, which are based on either a hydraulic system $^{10,12,20,28-31}$ or on an electrical analogue $e^{8,16,20,32}$. The hydraulic system approach (referred to as HydGro) considers capacitance as a variable that depends on the water content of storage tissue, while the electrical analogue approach (referred to as RcGro) takes capacitance as a constant. These models allow assessment of physiological characteristics that are difficult to measure (e.g., hydraulic resistance, hydraulic capacitance, and cell wall extensibility).

Despite their significant role in facilitating the study of water transfer in the soil-plant continuum ${ }^{26,27,33}$, the Ohm's Law based models and their extended versions have a few drawbacks. First, the steady state assumption that underlies the Ohm's Law models makes them inappropriate for describing natural scenarios, which are mostly characterized by transient flows at a rate less than the maximum ${ }^{34}$. This is due to continual fluctuations in atmospheric evaporative demand and stomatal conductance ${ }^{35}$, water redistribution or non-uniform water sup$\mathrm{pl}^{36}$, and water flow disconnection resulting from stomatal closure, cavitation, and root shrinkage. Second, Ohm's Law based models do not account for the retardation of water into and through the plant (i.e., actual time lag between transpiration and water uptake from the soil) because of the assumption of a linear response of water flux to potential gradient. Root resistance depends on flux and soil depth ${ }^{37-41}$ as well as the activity of fine $\operatorname{roots}^{1,36}$. Field experiments indicate that water flow from soil to plant is more than a simple linear flow ${ }^{42,43}$. Third, 
Ohm's Law based models neglect water transfer among different parts of a plant driven by water potential sub-gradients. Fourth, Ohm's Law based models were mostly verified using trees in terms of the relations between diurnal stem radius variation and tree water uptake $e^{8,10,12,16,20,28,30,32}$. As a result, the models might not be appropriate to herbaceous plants like agricultural crops. The same or similar limitations also exist in other water uptake models, leading to a lack of mechanistic understanding of the transient and nonlinear nature of plant water uptake. We thus proposed to evaluate plant water uptake based on an advanced electrical network (series RLC circuit theory), which includes "resistors," "capacitors," "inductors," and "fuses" that could reflect the dynamics of plant hydraulic architecture at varying scales-from cell to tissue and organ.

\section{Results}

Water uptake hysteresis. Figure 1 demonstrates that water uptake is positively related to water potential difference $(\Delta \Psi)$ between soil and leaf, following different paths in the morning and the afternoon. The results show that the water uptake rate is significantly larger in the morning than in the afternoon at the same magnitude of potential difference between soil and leaf in all of the 16 days of measurements. Such a difference indicates a significant hysteresis phenomenon in plant water uptake. Theoretically, hysteresis represents a retardation
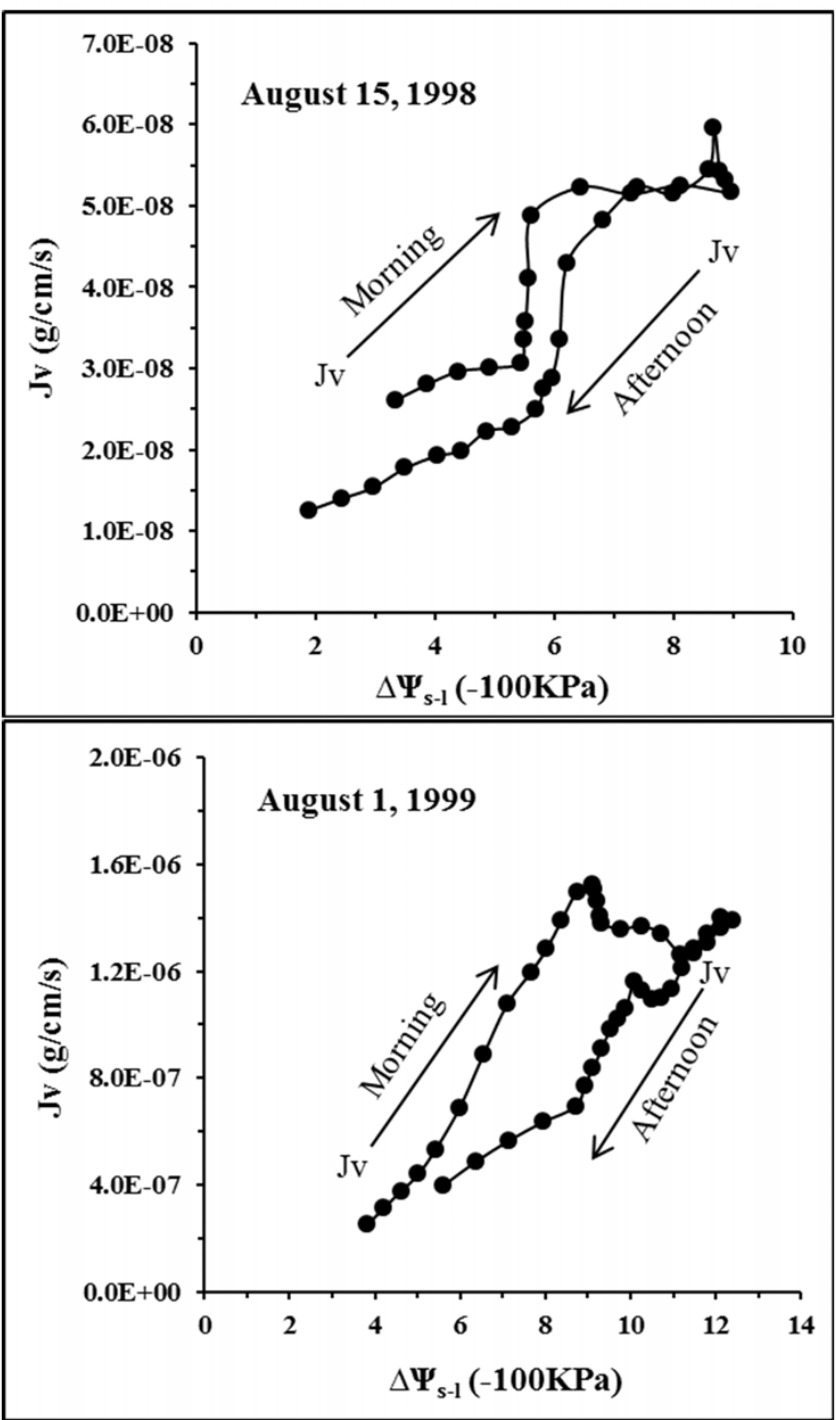

Figure $1 \mid$ Hysteretic relation between soil-leaf water potential difference $\left(\Delta \Psi_{\mathrm{s}-1}\right)$ and water uptake rate $\left(\mathrm{J}_{\mathrm{v}}\right)$. of the response of water flow to water potential change in a nonlinear manner (i.e., water flow lags behind transpiration demand). The extent of hysteresis (i.e., maximum disparity in uptake rate at a certain potential difference) depends on the history of water uptake and the status of plant water conditions (e.g., xylem cavitation and root-soil contact). Our results demonstrate that the water uptake hysteresis was 1-2 orders smaller in 1998, which was a relatively wet year with mean soil potential of $-20 \mathrm{kPa}$ and fluctuation between $-5 \mathrm{kPa}$ to $-33 \mathrm{kPa}$ during the experimental period, than in 1999 , which was a relatively dry year with mean soil potential of $-60 \mathrm{kPa}$ and a gradual increase from $-7 \mathrm{kPa}$ to $-83 \mathrm{kPa}$ during the experimental period (Figure 1). We attribute this difference to the higher availability of soil water, larger water storage and connectivity in xylem, a smaller gradient in soil-leaf potential, and better soil-root contact in the wetter environment.

Mechanistic model formulation. Mass flow of water can be described by a traditional transport equation. For hydraulic flow through cylindrical tubes, the hydraulic conductance is a function of the tube radius and fluid viscosity, as follows

$$
J_{v}(t)=\left(\frac{r^{2}}{8 \eta}\right) \frac{\Delta \Psi(\mathrm{t})}{S}
$$

where $J_{\mathrm{v}}(\mathrm{t})$ is the volume flux density $\left(\mathrm{m}^{3} / \mathrm{m}^{2} / \mathrm{s}\right)$ that is equal to an average velocity $(\mathrm{m} / \mathrm{s})$ at time $t, r$ is the tube radius $(\mathrm{m}), \eta$ is the dynamic viscosity of fluid $(\mathrm{kg} / \mathrm{m} / \mathrm{s}$ or $\mathrm{Pa} \mathrm{s}), S$ is the tube length (m), and $\Delta \Psi$ is potential difference $\left(\mathrm{kg} / \mathrm{m} / \mathrm{s}^{2}\right.$ or $\left.\mathrm{Pa}\right)$. This equation, or corresponding versions, is referred to as Poiseuille's Law, indicating that the average flow rate through unit cross-sections of a tube increases with the square of the tube radius.

Given the complexity of the transfer pathways of water through the soil-plant continuum, steady-state flow is usually calculated, rather than by Poiseuille's Law, by using simplified "black-box" resistance models ${ }^{23}$ like

$$
J_{v}(t)=\frac{\Psi_{s}(t)-\Psi_{l}(t)}{R_{s-l}(t)}
$$

where $\Psi_{\mathrm{s}}$ and $\Psi_{1}$ are the water potentials of the soil and leaf, respectively, and $R_{\mathrm{s}-\mathrm{l}}\left(\mathrm{kg} / \mathrm{m}^{2} / \mathrm{s}\right)$ denotes hydraulic resistances between the soil and leaf. The concepts embedded in Equation (2) (van den Hornert's model) are illustrated in Figure 2b. The transpirating plant usually sets up a gradient of water potential between soil and leaf so that water flows ${ }^{4}$. The flux through soil-plant system is controlled by the rate of water loss through stomata. Thus, leaf water potential can be regarded as an indirect factor that controls water flow through the plant by exerting an effect on stomatal resistance ${ }^{45}$.

Although the steady state model (Equation 2) has been widely applied, many studies found that it fails to account for hysteresis, a nonlinear phenomenon that is frequently observed from the relations between $\Psi_{1}$ and $J_{\mathrm{v}}{ }^{46-49}$. This type of response is attributed to the effect of diurnal changes in plant water storage because water storage could delay stomatal closure ${ }^{35,50-52}$. As in previous studies, we considered the effect of hysteresis by introducing hydraulic capacitance ( $C$ in $\mathrm{m}^{2} \mathrm{~s}^{2} / \mathrm{kg}$ or $\mathrm{m} / \mathrm{Pa}$ ) into the steady-state van den Hornert model, as follows

$$
J_{v}(t)=\frac{\Psi_{s}(t)-\Psi_{l}(t)}{R_{s-l}(t)}-C \frac{d \Psi_{l}(t)}{d t}
$$

By analogy with electrical capacitance, hydraulic capacitance of any part of the system is defined as the ratio of change in tissue water content ( $\mathrm{Q}$ in $\mathrm{m}^{3} / \mathrm{m}^{2}$ ) with potential $\left(\Psi \text { in } \mathrm{kg} / \mathrm{m} / \mathrm{s}^{2} \text { or } \mathrm{Pa}\right)^{53}$, given by $\mathrm{C}=d \mathrm{Q} / d \Psi$. Hydraulic capacitance is formed by changes in water storage in the xylem, coarse roots, and thick leaves $(d Q)$, and changes in potential $(d \Psi)$. When a capacitor is faced with an increasing $\Psi$ (i.e., storing water), it acts as a source-dropping $\Delta \Psi$ as it supplies 


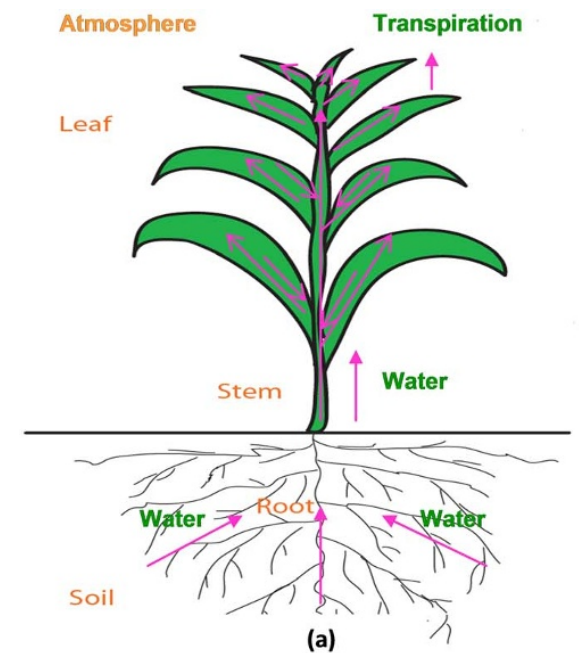

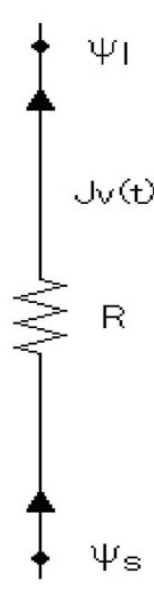

(b)

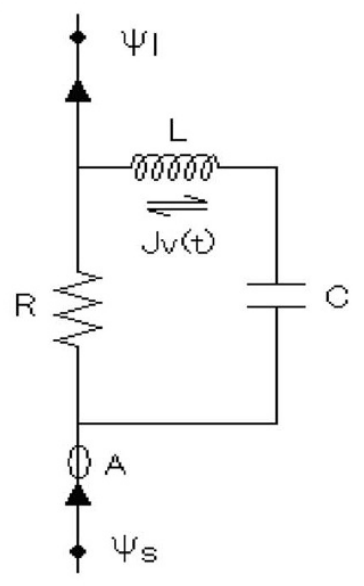

(c)

Figure $2 \mid$ Electric analogy of water flow through soil-plant system: (a) soil-plant system, (b) traditional steady state model, and (c) non-steady state model. $\Psi_{\mathrm{s}}$ - soil water potential, $\Psi_{\mathrm{l}}$ - leaf water potential, $\mathrm{J}_{\mathrm{v}}(\mathrm{t})$ - water uptake rate, $\mathrm{L}$-inductance, $\mathrm{R}$-flow resistance, C—capacitance, A-contact potential.

water to the leaf, like a battery. When a capacitor is faced with a decreasing $\Psi$ (i.e., depleting water), it acts as a sink, creating $\Delta \Psi$ as it stores the water in the xylem and coarse roots supplied by the soil via fine roots, like a resistor. The total $R$ and $C$ of the soil-plant system can be estimated with Equation (3) from measured diurnal changes in $\Psi_{\mathrm{l}}, \Psi_{\mathrm{s}}$, and $J_{\mathrm{v}}$. The sign of the second term on the right-hand side of Equation (3) is negative because water flows out of storage (adding to $\left.J_{\mathrm{v}}\right)$ when $d \Psi_{l}(t) / d t$ is negative. The hydraulic capacitance $(C)$ of the plant, which is considered varying with plant water conditions in the non-steady-state model, serves as a buffering function to adjust the magnitude of transpiration-induced xylem tension and associated cavitation resistance for alleviating plant safety versus efficiency trade-offs ${ }^{35}$. The value of $C$ reflects a hydraulic regime of the tissue, and its change is useful for comparison of plant tissues of very different quantities, shapes, and/or sizes. Note that steady-state experiments conducted in controlled environments would not be subject to the effect of the capacitance, because the value of $d \Psi_{l}(t) / d t$ becomes zero under steady-state conditions. In that case, Equation (3) reverts to the simple steady state model, as expressed by Equation (2).

Further, to understand and describe the hydraulics of water transport in plants, one needs to simultaneously measure water potentials and flow rates. However, precise measurement of leaf potential is difficult on short time scales (e.g., seconds to minutes). A few experiments have shown that the water uptake rate of plants (or roots) in terms of $J_{\mathrm{v}}$ has instantaneous features (e.g., fluctuations or pulses of water flow), especially at low leaf potential and large $J_{\mathrm{v}}{ }^{54-57}$. This phenomenon is mostly caused by the spatiotemporal heterogeneity of water flow rates in different parts of the 3-D plant architecture. This is plausible because leaf potentials vary with the heights and positions of leaves on the stem. Top leaves receive more solar radiation, lowering water potential (or reducing water availability), while low leaves are less exposed to radiation causing large potential (or increasing water availability). Thus, we assume there is an "inductance" effect, as instantaneous water flow rates at different parts of the plant may affect the average driving force of water flow in the plant. We also assume the presence of biological contact potential ( $A$ in $\mathrm{kg} /$ $\left.\mathrm{m} / \mathrm{s}^{2}\right)^{39,58}$, which acts like a "fuse" in an electrical circuit and is susceptible to environmental stress due to more rapid decreases in rootwater potential than in soil-water potential ${ }^{1,17,59}$. We introduced the principle of "inductance" and "fuse" into Equation (3), resulting in the following RCL circuit-based non-steady state model:

$$
J_{v}(t)=\frac{\Psi_{s}(t)-\Psi_{l}(t)}{R_{s-l}}-\frac{L d J_{v}(t)}{R_{s-l} d t}-C \frac{d \Psi_{l}(t)}{d t}-\frac{A}{R_{s-l}}
$$

This model is diagrammatically shown in Figure 2c. The consideration of "inductance" effect reflects the heterogeneous response of the leaf system architecture to climate. The water potential difference $\left(\Delta \Psi_{\mathrm{c}}\right)$ induced by hydraulic inductance is defined as

$$
\Delta \Psi_{c}=-L \frac{d J_{v}(t)}{d t}
$$

where $L$ is the inductance coefficient in $\mathrm{kg} / \mathrm{m}^{2}$. The inductance, which is formed by the heterogeneity of leaf water potentials at different heights of the plant, resists changes in flow rate $d J_{\mathrm{v}}(\mathrm{t})$. When an inductor (i.e., leaf system) is faced with an increasing $J_{v}$, it (e.g., upper leaves) acts as a sink, dropping potential as it consumes water, like a resistor. When an inductor is faced with a decreasing $J_{v}$, it (e.g., lower leaves) acts as a source, creating potential as it supplies stored water to upper leaves, like a battery. The relation between $L$ and $C$ can be expressed by:

$$
R_{0}=\sqrt{\frac{4 L}{C}}
$$

where $R_{0}$ represents a critical resistance of flow. According to the series RCL circuit theory, when actual $R$ gets close to $R_{0}, J_{v}$ becomes stable; otherwise, $J_{v}$ fluctuates with a frequency $f(1 / s)$ :

$$
f=\frac{1}{2 \pi \sqrt{L C}}
$$

To consider the dependence of overall soil water availability on the profiles of soil water potential and root density, we adopt an effective soil water potential $\Psi_{s}(\mathrm{t})$ for Equation (4) as calculated by ${ }^{56}$

$$
\Psi_{s}(t)=\frac{\sum_{i} \lambda_{r, i}(t) \Psi_{s, i}(t)}{\sum_{i} \lambda_{r, i}(t)}
$$

where $\Psi_{\mathrm{s}, \mathrm{i}}$ and $\lambda_{\mathrm{r}, \mathrm{i}}$ refer to soil water potential and root length density in the $i$ th layer of soil ( $\mathrm{i}=1,2, \ldots 12 ; 5 \mathrm{~cm}$ thickness in each layer), respectively.

Non-steady-state analysis. Figures $3 a$ and $3 b$ compares the measured and simulated results of water uptake rates using the steady-state model (Equation 2) and the non-steady-state model (Equation 4). Effectiveness of Equation 4 in capturing the fluctuations of uptake rates is demonstrated in Figure $3 \mathrm{~d}$, as compared to the results with Equation 2 in Figure 3c, based on the data collected on August 1, 1999. Similar results were obtained for 


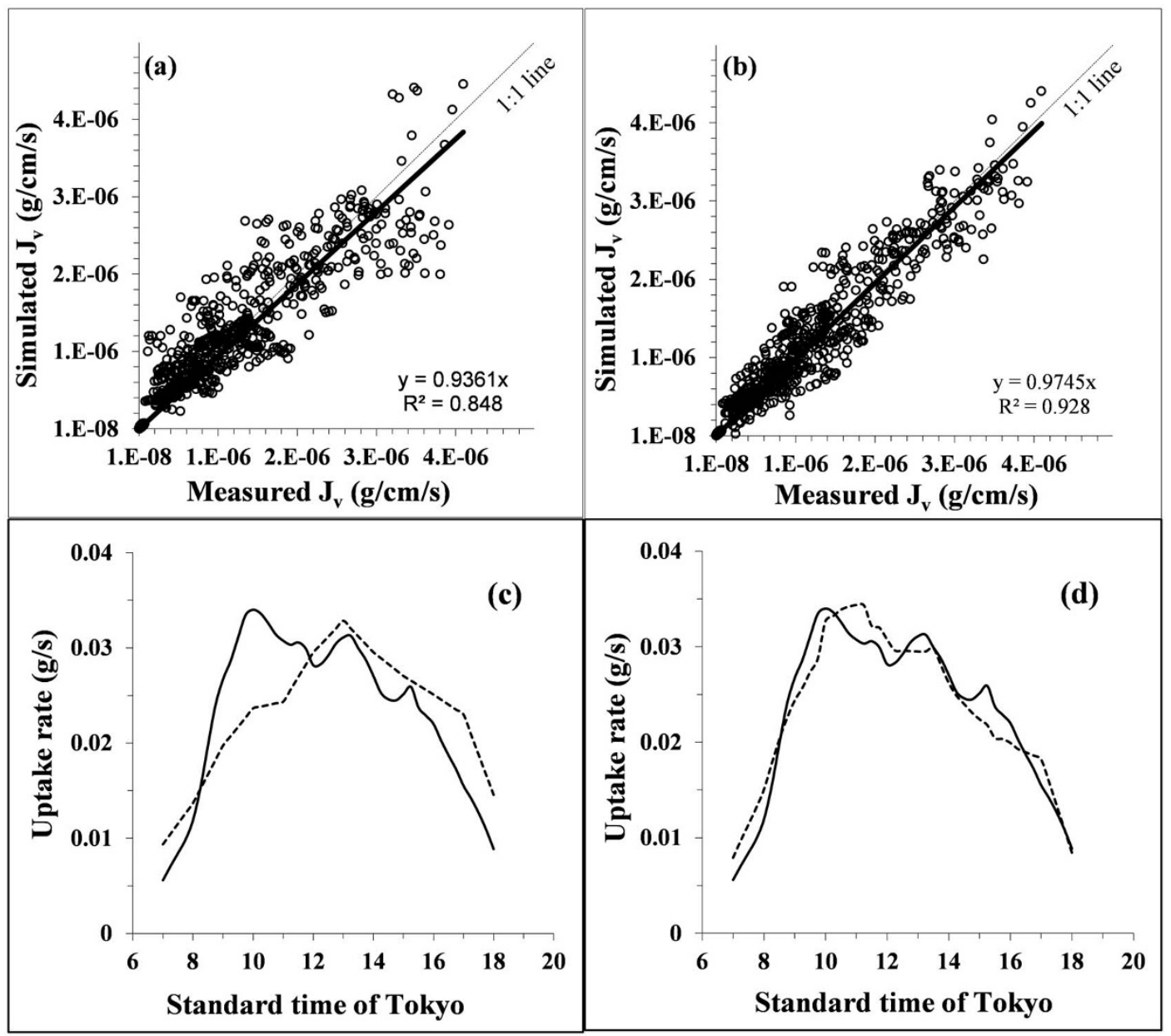

Figure 3 Comparison of steady state model (a) and non-steady state model (b) based on the data observed in 1998 and 1999 . The uptake curves are the sap flow rates observed (solid line) on August 1, 1999 and simulated results (dashed line) using steady state model (c) and non-steady state model (d). The measured data in (a) and (b) are the 15-minute average sap flow rates observed in eight days of each year of $1998(\mathrm{n}=434)$ and $1999(\mathrm{n}=481)$.

other observation days. It is evident that taking the effects of hydraulic "capacitance," "inductance," and "fuse" into consideration significantly improves the description of water uptake dynamics. The contribution of these three parameters to the goodness of fit differed among the observation days. Inclusions of $C, L$, and $A$ in the model increased the values of the coefficient of determination $\left(R^{2}\right)$ by $0.10 \pm 0.07,0.11 \pm 0.05$, and $0.10 \pm 0.06$, respectively, in the two years. The results suggest that plant water storage, water transfer among different parts, and biological contact potential are three biophysical mechanisms that dominate the instantaneous non-steady nature of water flow between soil and plant.

Table 1 provides the mean values of parameters fitted with Equation (4) using the data collected from a corn field during eight days in each year of 1998 and 1999 . The value equality of $R_{0}$ to $R$ in 1998 suggests that the instantaneous change of water uptake rates with time $\left(d \mathrm{~J}_{\mathrm{v}} / d \mathrm{t}\right)$ was relatively small (or flow was continuous) in a wet year. In comparison, instantaneous water uptake fluctuated greatly (or water was supplied in pulses of a certain frequency) in a dry year, as indicated by the larger value of $R_{0}$ than $R$ in 1999. Such dependence of uptake stability on soil water availability is consistent with the spatial distribution of leaf water potential at different heights of the plant (Figure 4). Our measurements show that leaf water potentials significantly decreased with the height of leaves when soil was dry, but there was no significant difference when soil was wet. As expected, water storage in plant in a wet year resulted in a value of $C$ that is approximately near thirty times that in a dry year. This result shows a negative relation between capacitance and hysteresis of water uptake. Consistent with theoretical assumptions, the negative value of $A$ in the wet year suggests a better interfacial contact between soil and root, due likely to the presence of more active fine roots or larger hydraulic conductivity in the rhizosphere. The positive value

Table 1 | Non-steady State Model Parameters

\begin{tabular}{lccc} 
Parameter & Wet year (1998) & Dry year (1999) & Unit \\
\hline R & $(2.2 \pm 0.2) \times 10^{8}$ & $(5.7 \pm 3.5) \times 10^{6}$ & $\mathrm{~kg} / \mathrm{m}^{2} / \mathrm{s}$ \\
C & $(2.1 \pm 1.2) \times 10^{-6}$ & $(7.5 \pm 2.3) \times 10^{-8}$ & $\mathrm{~m} \mathrm{~m}^{2} / \mathrm{kg}$ \\
$\mathrm{L}$ & $(-8.5 \pm 4.7) \times 10^{10}$ & $(-2.1 \pm 1.2) \times 10^{9}$ & $\mathrm{~kg} / \mathrm{m}^{2}$ \\
A & $-1.85 \pm 2.49$ & $1.55 \pm 1.89$ & $\mathrm{~kg} / \mathrm{m} / \mathrm{s}^{2}$ \\
L/R & $-385.9 \pm 279.2$ & $-365.6 \pm 312.1$ & $\mathrm{~s}$ \\
$R_{0}=2(\mathrm{~L} / \mathrm{C})^{0.5}$ & $(3.33 \pm 2.54) \times 10^{8}$ & $(3.31 \pm 2.36) \times 10^{8}$ & $\mathrm{~kg} / \mathrm{m}^{2} / \mathrm{s}$ \\
$f=1 /\left[2 \pi(\mathrm{LC})^{0.5}\right]$ & -- & 56 & $1 / \mathrm{s}$
\end{tabular}



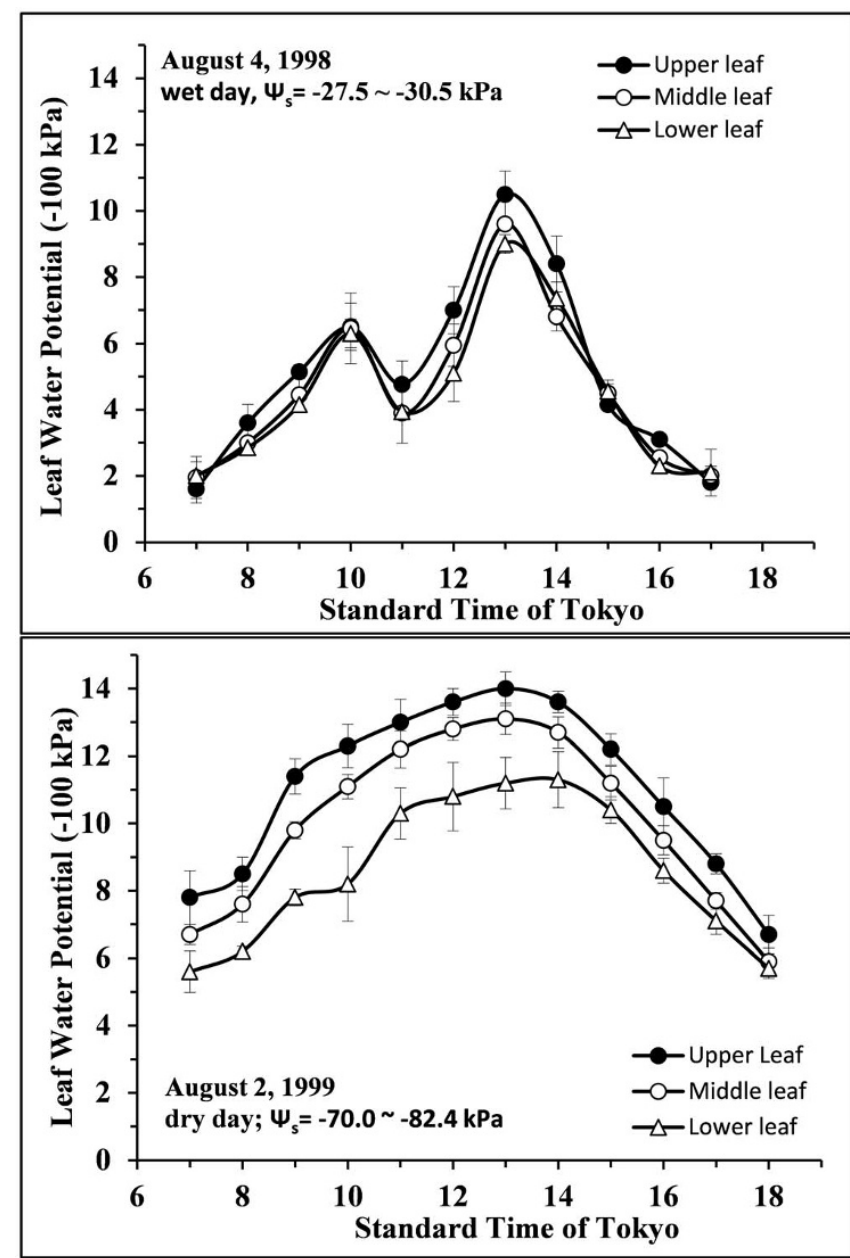

Figure $4 \mid$ Daytime variations of leaf water potential at different heights from the ground on representative days in 1998 and 1999. $\Psi_{\mathrm{s}}$ denotes effective soil water potential calculated with Eq. 8 .

of $A$ in the dry year indicates possible interfacial interference caused by, for instance, a steep gradient of water potential over the soil-root depletion zone, shrinkage of fine roots during the soil drying process, and/or slower recovery of root physiology during the soil rewetting process. The negative value of the fitted $L$ suggests that water transfer among leaves or roots was a significant phenomenon. The transfer was much more significant under higher water availability conditions, as indicated by the forty times larger absolute value of $L$ in a wet year (1998) than in a dry year (1999). The ratio of $L$ to $R$ indicates the affordability of a maize plant to the fluctuation of water flow rate while remaining healthy or recoverable conditions (i.e., tolerance to the lowest water supply rate). The similarity of this ratio in both years suggests that the value of $\mathrm{L} / \mathrm{R}$ represents a kind of plant constant.

\section{Discussion}

The hysteretic uptake suggests that a soil-plant system is not a simple or homogeneous resistance network as assumed in the analogy between Ohm's Law and Poiseuilles' Law. Water storage (increasing capacitance) in the plant could reduce hysteresis. A few studies have suggested that the discharge of stored water in the xylem into the transpiration stream (decreasing capacitance) could prolong the time (increasing hysteresis) required for xylem tension and flow to attain steady state ${ }^{35,60-62}$. Water passes from the soil to the plant in more than a simple linear flow, as is demonstrated by the "inductance" effect and previous studies. Zweifel et al. ${ }^{59}$ observed hysteresis patterns between crown water potential and stomatal aperture of Pubescent Oak and Scots pine. Hellkvist et al. ${ }^{63}$ noted a six-hour difference between a drop in foliage water potential and a drop in root water potential in relatively young Picea sitchensis (Bong.) Carr. Trees. The analysis by Dalton ${ }^{42}$ predicts a nonlinear response of water flux to potential gradient that drives the flux into and through plant. Similarly, a few other experiments reported nonlinear pattern of root water uptake $e^{48,49,52,64,65}$. The steep decrease of water potential (increasing resistance) over the soil-root depletion zone, which leads to "fuse" effect and is accelerated by root water uptake, is assumed to be partially responsible for such non-linear behaviors ${ }^{17}$. In spite of this, how a plant could effectively adjust a moving sink and source during water uptake process remains an open question. Existing data might not be able to clarify this question because few efforts have been made to quantify the multi-path or bifurcation transfer of water among different parts of the soil-plant system as driven by the heterogeneous hydraulics of the system ${ }^{12,30}$.

The series RLC circuit theory based model provides a relatively complete, straightforward mechanistic framework for evaluating water flow through the soil-plant continuum and analyzing how plant configuration and corresponding hydraulic architecture could help the plant adapt to water stress by moving sink or source. For instance, large water storage in the plant is a critical factor in maintaining long-distance water transport and reducing the negative impacts of a high transpiration rate on plant physiology ${ }^{66}$. The "inductance" effect, which reflects the allocation of water extracted from the soil into individual parts of the plant, is another important factor that increases plant tolerance to water scarcity. Plant configuration (e.g., spatial distribution of leaves) and hydraulic compensation among different parts, which can induce a larger value of $L$, might serve as better protection from physiological damage under water stress. The similarity of the magnitude of $R_{0}$ and the ratio of $L$ to $R$ in the wet (1998) and dry (1999) years implies that these characteristic parameters, which integrate the effects of xylem water storage and plant configuration, might remain constant for a specific plant under different environmental conditions. This, however, needs verification through experiments on other plant species of different plant configurations (e.g., trees) and those of different water-carbon efficiencies (e.g., C3 plants). The estimated frequency of water uptake pulse, 0.018 cycle per second (Table 1 ), indicates that the flow pause very likely occurred approximately every minute in the dry year. This pulse interval has a similar time scale to that of the experimental finding by Inenko et al. ${ }^{57}$. They found that maize root response to water stress consists of a series of time-dependent stages. A transient pulsed jump in diffusional water transfer detected several seconds after beginning the osmotic treatment is associated with the spread of the wave of hydraulic pressure along the root. This research suggests that the plant has a self-protection strategy under water stress, which is determined by the hydraulic architecture (including water storage, potential gradients, and flow connectivity) and heterogeneous responses of different parts of plants to environmental change. It has been reported that the hydraulic architecture might affect the regulation of stomatal aperture via plant hormones ${ }^{59}$. Compared with existing mathematical and empirical models, the non-steady-state model presented in this study might be more useful as an inverse approach to analyzing water uptake response and the role of plant configuration, guiding field irrigation schedules, and understanding water balance between the biosphere and the atmosphere. Future work should address at least three questions, such as (i) how plant configuration or architecture determines the network of resistance to water flow from soil to leaf, (ii) how instantaneous exchange of "messages" is made among soil, roots, and aerial parts of the plant to guide water uptake $^{67}$, and (iii) how the exchange is affected by water pre-storage in tissues, nutrient availability, and metabolic activity ${ }^{68}$. These analyses might have implications for plant adaptation under changing climate, field crop management, and vegetation selection for adverse environments. 


\section{Methods}

Our models were tested using the data from the experiments carried out over a fourweek period between July 15 and August 20 in 1998, and between 21 July and August 22 in 1999 on an experimental farm (latitude $35^{\circ} 46^{\prime} \mathrm{N}$, longitude $139^{\circ} 54^{\prime} \mathrm{E}$, altitude $7.9 \mathrm{~m}$ ) at Chiba University, Japan. Maize (Zea mays L.) was planted on May 25, 1998 and on April 30, 1999, in a field with an area of $400 \mathrm{~m}^{2}$. The within-row spacing was $0.4 \mathrm{~m}$ and the inter-row distance was $0.7 \mathrm{~m}$. Before sowing each year, chemical fertilizers were applied to the field at $60 \mathrm{~kg}$ nitrogen/ha, $44 \mathrm{~kg}$ phosphorus $/ \mathrm{ha}$, and $75 \mathrm{~kg}$ potassium/ha. The field was not irrigated during plant growth. The soil was a Kanto fine sandy loam developed from volcanic ash.

On the investigation days, a pressure chamber method (SOILMOISTURE, 3005) was used to make hourly measurements from 7:00 to 18:00 on the water potential of leaves in the upper, medium, and lower positions of the stems of three plants near the plants for sap flow measurement. Water potential of eight to ten roots taken at a depth $10-20 \mathrm{~cm}$ in the soil of the three plants was also measured. Meanwhile, soil water potentials were recorded using ceramic-tipped tensiometer probes (DIK-3100, Daiki Rika), which were installed vertically at each $10-\mathrm{cm}$ depth of three $60-\mathrm{cm}$ deep field profiles near the plants for sap flow measurement.

Plant water uptake was represented by xylem sap flow, which was measured using a heat balance method with the gauges (Dyanmax, SGB25) installed on the base of plant stems. Total root length in each soil layer was determined using a line-intercept sampling method immediately after the field experiments. Roots in twelve soil layers (each $70 \times 40 \times 5 \mathrm{~cm}^{3}$ ) at each plant location were collected along the 60 -cm deep soil profiles.

1. Jackson, R. B., Sperry, J. S. \& Dawson, T. E. Root water uptake and transport: using physiological process in global predictions. Trend Plant Sci. 5, 482-488 (2000).

2. Sperry, J. S., Stiller, V. \& Hacke, U. G. Xylem hydraulics and the soil-plantatmosphere continuum: opportunities and unresolved issues. Agron. J. 95, 1362-1370 (2003).

3. Green, S. R., Kirkham, M. B. \& Clothier, B. E. Root uptake and transpiration: from measurements and models to sustainable irrigation. Agri. Water Manag. 86, 165-176 (2006).

4. Chapman, N., Miller, A. J., Lindsey, K. \& Whalley, W. R. Roots, water, and nutrient acquisition: let's get physical. Trends in Plant Sci. 17, 701-710 (2012).

5. Gardner, W. R. Dynamic aspects of water availability to plants. Soil Sci. 89, 63-73 (1960)

6. Gardner, W. R. Relation of root distribution to water uptake and availability. Agron. J. 56, 41-45 (1964)

7. Molz, F. J. \& Remson, I. Extraction term models of soil moisture use by transpiring plants. Water Resour. Res. 6, 1346-1356 (1970).

8. Landsberg, J. J., Blanchard, T. W. \& Warrit, B. Studies on the movement of water through apple trees. J. Exp. Bot. 27, 579-596 (1976).

9. Feddes, R. A., Kowalik, P. J., Malinka, K. K. \& Zaradny, H. Simulation of field water use and crop yield (John Wiley and Sons, Pudoc Wageningen, 1978).

10. Edwards, W. R. N., Jarvis, P. G., Landsberg, J. J. \& Talbot, H. A dynamic model for studying flow of water in single trees. Tree Physiol. 1, 309-324 (1986).

11. Prasad, R. A linear root water uptake model. J. Hydrol. 99, 297-306 (1988).

12. Tyree, M. T. A dynamic-model for water-flow in a single tree-evidence that models must account for hydraulic architecture. Tree Physiol. 4, 195-217 (1988).

13. Jarvis, N. J. A simple empirical model of root water uptake. J. Hydrol. 107, 57-72 (1989).

14. Gardner, W. R. Modeling water uptake by roots. Irrig. Sci. 12, 109-114 (1991).

15. Stedule, E. Water uptake by plant roots: an integration of views. Plant Soil 226, 45-56 (2000).

16. Lhomme, J. P., Rocheteau, A., Ourcival, J. M. \& Rambal, S. Non-steady-state modelling of water transfer in a Mediterranean evergreen canopy. Agric. For. Meteorol. 108, 67-83 (2001).

17. Tuzet, A., Perrier, A. \& Leuning, R. A coupled model of stomatal conductance, photosynthesis and transpiration. Plant Cell Environ. 26, 1097-1116 (2003).

18. Roose, T. \& Fowler, A. C. A model for water uptake by plant roots. J. Theoretical Bio. 228, 155-171 (2004).

19. Li, K. Y., Jong, R. De., Coe, M. T. \& Ramankutty, N. Root-water-uptake based upon a new water stress reduction and an asymptotic root distribution function. Earth Interactions 10, 1-22 (2006).

20. Steppe, K., De Pauw, D. J. W., Lemeur, R. \& Vanrolleghem, P. A. A mathematical model linking tree sap flow dynamics to daily stem diameter fluctuations and radial stem growth. Tree Physiol. 26, 257-273 (2006).

21. Dixon, H. H. \& Joly, J. On the ascent of sap. Phil. Trans. Royal Soc., London B. Biol. Sci. 186, 563-576 (1894)

22. Gradmann, H. Untersuchungen über die Wasserverhältnisse des Bodens als Grundlage des Pflanzenwachstums, I. Jahrb. Wiss. Bot. 69, 1-100 (1928).

23. Van den Honert, T. H. Water transport as a catenary process. Faraday Soc. Discuss. 3, 146-153 (1948).

24. Philip, J. R. Plant water relations: some physical aspect. Annual Rev. Plant Physiol. 17, 245-268 (1966)

25. Hopmans, J. W. \& Bristow, K. L. Current capabilities and future needs of root water and nutrient uptake modeling. Adv. Agron. 77, 103-183 (2002).

26. Jarvis, P. G., Edwards, W. R. N. \& Talbot, H. Mathematics and Plant Physiology. (Academic Press, London, 1981).
27. Hunt, E. R. Jr., Running, S. W. \& Federer, C. A. Extrapolating plant water flow resistances and capacitances to regional scales. Agric. For. Meteorol. 54, 169-195 (1991).

28. Zweifel, R., Item, H. \& Häsler, R. Link between diurnal stem radius changes and tree water relations. Tree Physiol. 21, 869-877 (2001).

29. Messinger, S. M., Buckley, T. N. \& Mott, K. A. Evidence for involvement of photosynthetic processes in the stomatal response to $\mathrm{CO}_{2}$. Plant Physiol. 140, 771-778 (2006).

30. Cermák, J., Kucera, J., Bauerle, W. L., Phillips, N. \& Hinckley, T. M. Tree water storage and its diurnal dynamics related to sap flow and changes in stem volume in old-growth Douglas-fir trees. Tree Physiol. 27, 181-198 (2007).

31. De Pauw, D. J. W., Steppe, K. \& De Baets, B. Identifiability analysis and improvement of a tree water flow and storage model. Math. Biosci. 211, 314-332 (2008).

32. Steppe, K., De Pauw, D. J. W. \& Lemeur, R. Validation of a dynamic stem diameter variation model and the resulting seasonal changes in calibrated parameter values. Ecol. Model. 218, 247-259 (2008).

33. Kirkham, M. B. Physical model of water in a split-root system. Plant Soil 75, 153-168 (1983).

34. Somma, F., Clausnitzer, V. \& Hopmans, J. W. Modeling of transient threedimensional soil water and solute transport with root growth and water and nutrient uptake. Plant Soil 202, 281-293 (1998).

35. Sperry, J. S., Meinzer, F. C. \& McCulloh, K. A. Safety and efficiency conflicts in hydraulic architecture: scaling from tissues to trees. Plant Cell Environ. 31, 632-645 (2008)

36. Bruckler, L., Lafolie, F., Doussan, C. \& Bussieres, F. Modeling soil-root water transport with non-uniform water supply and heterogeneous root distribution. Plant Soil 260, 205-224 (2004).

37. Passioura, J. B. Hydraulic resistance of plants. I. constant or variable? Aust. J. Plant Physiol. 11, 333-339 (1984)

38. Steudle, E. Water transport across roots. Plant Soil 167, 79-90 (1994).

39. Stirzaker, R. J. \& Passioura, J. B. The water relations of the root-soil interface. Plant Cell Environ. 19, 201-208 (1996).

40. Lhomme, J. P. Formulation of root water uptake in a multi-layer soil-plant model: does van den Honert's equation hold? Hydrol. Earth Syst. Sci. 2, 31-40 (1998).

41. Guswa, A. J. Effect of plant uptake strategy on the water-optimal root depth. Water Resour. Res. 46, W09601 (2010).

42. Dalton, F. N., Raats, P. A. C. \& Gardner, W. R. Simultaneous uptake of water and solute by plant roots. Agron. J. 67, 334-339 (1975).

43. Yu, G.-R., Zhuang, J. \& Nakayama, K. Root water uptake and profile soil water as affected by vertical root distribution. Plant Ecol. 189, 15-30 (2007).

44. Wheeler, T. D. \& Stroock, A. D. The transpiration of water at negative pressures in a synthetic tree. Nature 455, 208-212 (2008).

45. Passioura, J. B. Water transport in and to roots. Annual Rev. Plant Physiol. Plant Mol. Bio. 39, 245-265 (1988).

46. Berger, A. Transpiration, potential hydrique et resistance a la circulation de l'eau dans une culture. d'Helianthus annuus L. Oecol. Plantarum 4, 123-154 (1969).

47. Jarvis, P. G. The interpretation of the variations in leaf water potential and stomatal conductance found in canopies in the field. Phil. Trans. Royal Soc., London B 273, 593-610 (1976).

48. Sterne, R. E., Kaufmann, M. R. \& Zentmyer, G. A. Environmental effects of transpiration and leaf water potential in avocado. Physiol. Plantarum 41, 1-6 (1977).

49. Jones, H. G. Modeling diurnal trends of leaf water potential in transpiring wheat. J. Applied Ecol. 15, 613-626 (1978).

50. Biscoe, P. V., Cohen, Y. \& Wallace, J. S. Daily and seasonal changes in water potential in cereals. Phil. Trans. Royal Soc., London B. 273, 565-580 (1976).

51. Wallace, J. S., Clark, J. A. \& Mcgowan, M. Water relations of winter wheat, 4. Hydraulic resistance and capacitance in the soil-plant system. J. Agric. Sci. Camb. 100, 591-600 (1983).

52. Lafolie, F., Bruckler, L. \& Tardieu, F. Modeling root water potential and soil-root water transport: I. Model presentation. Soil Sci. Soc. Am. J. 55, 1203-1212 (1991).

53. Powell, D. B. B. \& Thorpe, M. R. Environmental Effects on Crop Physiology (Academic Press, London, 1977).

54. Choudhury, B. J. \& Idso, S. B. Evaluating plant and canopy resistances of fieldgrown wheat from concurrent diurnal observations of leaf water potential, stomatal resistance, canopy temperature, and evapotranspiration flux. Agri. Forestry Meteorol. 34, 67-76 (1985).

55. Or, D. \& Coelho, F. E. Soil water dynamics under drip irrigation: transient flow and uptake models. Trans. Am. Soc. Agric. Eng. 39, 2017-2025 (1996).

56. Zhuang, J., Nakayama, K., Yu, G.-R. \& Urushisaki, T. Estimation of root water uptake of maize: an ecophysiological perspective. Field Crop Res. 69, 201-213 (2001).

57. Ionenko, I. F., Dautova, N. R. \& Anisimov, A. V. Early change of water diffusional transfer in maize roots under the influence of water stress. Environ. Exp. Botany 76, 16-23 (2012).

58. Moreshet, S., Huang, B. \& Huck, M. G. Plant Roots: the Hidden Half (Marcel Dekker Inc., New York, 1996).

59. Zweifel, R., Steppe, K. \& Sterck, F. J. Stomatal regulation by microclimate and tree water relations: interpreting ecophysiological field data with a hydraulic plant model. J. Exp. Botany 58, 2113-2131 (2007). 
60. Williams, M. et al. Modelling the soil-plant-atmosphere continuum in a QuercusAcer stand at Harvard forest: the regulation of stomatal conductance by light, nitrogen and soil/plant hydraulic properties. Plant Cell Environ. 19, 911-927 (1996).

61. Phillips, N., Nagchaudhuri, A., Oren, R. \& Katul, G. Time constant for water transport in loblolly pine trees estimated from time series of evaporative demand and stem sapflow. Trees 11, 412-419 (1997).

62. Phillips, N. G., Oren, R., Licata, J. \& Linder, S. Time series diagnosis of tree hydraulic characteristics. Tree Physiol. 24, 879-890 (2004).

63. Hellkvist, J., Richards, G. P. \& Jarvis, P. G. Vertical gradients of water potential and tissue water relations in Sitka spruce trees measured with the pressure chamber. J. Appl. Ecol. 11, 637-668 (1974).

64. So, H. B., Aylmore, L. A. G. \& Quirk, J. P. The resistance of intact maize roots to water flow. Soil Sci. Soc. Am. J. 40, 222-225 (1976).

65. Aylmore, L. A. G., Hamza, G. \& Hamza, M. Water and solute movement to plant roots. Trans. 14 Intl. Cong. Soil Sci. Kyoto II, 124 (1990).

66. Stratton, L., Goldstein, G. \& Meinzer, F. C. Stem water storage capacity and efficiency of water transport: their functional significance in a Hawaiian dry forest. Plant Cell Environ. 23, 99-106 (2000).

67. Gollan, T., Passioura, J. B. \& Munns, R. Soil water status affects the stomatal conductance of fully turgid wheat and sunflower leaves. Aust. J. Plant Physiol. 13, 459-464 (1986).

68. Aroca, R., Porcel, R. \& Ruiz-Lozano, J. M. Regulation of root uptake under abiotic stress conditions. J. Exp. Bot. 63, 43-57 (2012).

\section{Acknowledgments}

This work was partially supported by the Japan Society for the Promotion of Science (JSPS) (Grant \# P97470)

\section{Author contributions}

J.Z. and G.-R.Y. contributed equally to this work. J.Z. performed field experiments and prepared the manuscript. G.-R.Y. helped with experimental implementation, data analysis, and model development. K.N. provided assistance in experimental design and financial support.

\section{Additional information}

Competing financial interests: The authors declare no competing financial interests.

How to cite this article: Zhuang, J., Yu, G.-R. \& Nakayama, K. A Series RCL Circuit Theory for Analyzing Non-Steady-State Water Uptake of Maize Plants. Sci. Rep. 4, 6720; DOI:10.1038/srep06720 (2014)

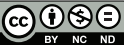

This work is licensed under a Creative Commons Attribution-NonCommercialNoDerivs 4.0 International License. The images or other third party material in this article are included in the article's Creative Commons license, unless indicated otherwise in the credit line; if the material is not included under the Creative Commons license, users will need to obtain permission from the license holder in order to reproduce the material. To view a copy of this license, visit http:// creativecommons.org/licenses/by-nc-nd/4.0/ 